\title{
Single versus bilateral mammary artery grafts in the setting of off-pump coronary revascularization: Survival benefit with bilateral mammary
}

Ana Lopez-Marco ${ }^{1}$, Aidil Syed ${ }^{1}$, Mabel Phillips Bn ${ }^{1}$, Jennifer Williams ${ }^{1}$, John Hogan Phd ${ }^{1}$, Joseph George $^{1}$, Junaid Mansoor ${ }^{1}$, Michael Ghebre Phd ${ }^{1}$, and Dheeraj Mehta ${ }^{1}$

${ }^{1}$ Affiliation not available

March 8, 2021

\begin{abstract}
OBJECTIVE To compare postoperative and long-term results (angina, myocardial and cerebrovascular events and coronary re-intervention) using single versus bilateral internal mammary arteries (SIMA vs. BIMA) in the setting of off-pump revascularisation (OPCAB) within a single-surgeon practice. METHODS Retrospective analysis of all isolated OPCAB performed in our institution by a single surgeon in the last 12 years. Two groups were analysed: SIMA ( $\mathrm{n}=681)$ and BIMA ( $=342)$. A propensity score matching was performed to compare the groups, reducing the sample to 684 patients. Follow-up (mean $6.5 \pm 3.5$ years) was done by telephone interviews or clinical visits, registering also late mortality and coronary re-intervention. Outcomes were compared to literature. RESULTS Demographic characteristics differed between groups, with BIMA offered predominantly to non-diabetic younger males (mean 59.4 years) with less comorbidity. In-hospital mortality was $2 \%$ for the SIMA group and $1 \%$ for BIMA ( $\mathrm{p}=0.18)$. Long-term mortality was also higher for the SIMA group $(2 \%$ vs. $1 \%$ at 1 year, $\mathrm{p}=0.22$ and $16 \%$ vs. $5 \%$ at 5 years, p < 0.001). Sternal wound infection was similar in both groups $(2-3 \%)$. Long-term follow-up revealed good freedom from angina (94\%) with low rates of neurological and myocardial events $(3 \%)$ or need for repeated revascularisation $(3 \%)$ in both groups. CONCLUSION BIMA offers long-term survival benefit with similar postoperative complications. Rates of deep sternal wound infection were comparable between the two groups.Excellent outcomes can be achieved with OPCAB BIMA in real world practice with adequate patient selection.
\end{abstract}

\section{AUTHORS:}

Ana Lopez-Marco MD ${ }^{a}$, Aidil Syed MD ${ }^{\mathrm{a}}$, Mabel Phillips BN ${ }^{\mathrm{a}}$, Jennifer Williams MD ${ }^{\mathrm{a}}$, John Hogan PhD ${ }^{\mathrm{a}}$, Joseph George MD ${ }^{\mathrm{a}}$, Junaid Mansoor MD ${ }^{\mathrm{a}}$, Michael Ghebre PhD ${ }^{\mathrm{b}}$, Dheeraj Mehta MD ${ }^{\mathrm{a}}$.

INSTITUTIONS AND AFFILIATIONS:

Department of Cardiothoracic Surgery ${ }^{\text {a }}$, University Hospital of Wales, Cardiff (United Kingdom)

Department of Biostatistics ${ }^{b}$, University Hospital of Leicester, Leicester (United Kingdom)

MEETING PRESENTATION:

This material was presented at the AATS International Coronary Congress, November 2016, New Delhi.

CORRESPONDING AUTHOR

Miss Ana Lopez-Marco

University Hospital of Wales 
Heath Park, Cardiff CF14 4XW (Wales, United Kingdom)

Tel: (+44) 0292074 2944; Fax: (+44) 02920745439

E-mail: analopez1000@hotmail.com

No funding was received for this study. No conflict of interest with industry to declare.

\section{INTRODUCTION}

The use of bilateral arterial mammary (BIMA) compared to single internal mammary artery (SIMA) in coronary revascularization has been suggested to improve long-term survival by several observational studies and meta-analysis. ${ }^{[1-10]}$

However, the only randomized control trial evaluating the long-term survival with BIMA has not proved any survival benefit with the used of BIMA. [11-15]

On the other hand, the routine use of BIMA is still limited by the higher morbidity and mortality associated with the technique, especially related to deep sternal wound infection (DSWI). ${ }^{[19,}$ 20]

The objective of this study was to compare the operative and long-term outcomes of patients using BIMA versus SIMA in the setting of off-pump coronary bypass surgery (OPCAB) in a single institution; all cases were undertaken by a single surgeon with experience in OPCAB surgery (over 1500 cases) whose default approach to surgical coronary revascularization is OPCAB.

\section{MATERIAL AND METHODS}

\section{Patient selection and data collection}

We conducted a retrospective analysis of prospectively electronically collected data of all patients who underwent isolated OPCAB in our center between 2003 and 2014. All cases were performed by the same surgeon. Preoperative characteristics, cardiovascular risk factors, postoperative complications and in-hospital mortality were prospectively recorded in our database Patients Administration and Tracking System (PATS).

Long-term follow-up was undertaken through clinical visits and/or telephone interviews to determine clinical status (functional class and residual angina), myocardial and cerebrovascular events and need for repeated revascularization. The follow-up data collection was undertaken between January and September 2016, with the majority being through telephone interview, as patients had already been discharged from the hospital follow-up system. Mortality data was obtained from the National Demographic Census.

The data used in this study was approved by the institutional review board, which deemed an individual consent form was not needed since no patient identifiable information was used.

\section{Operative technique:}

OPCAB is the default technique used by the author for isolated coronary revascularization, including emergency referrals. Surgical access was obtained through standard median sternotomy. The revascularization strategy for the SIMA group included LIMA-LAD and saphenous vein grafts (SVG) for the other targets. In the BIMA group, a LIMA-RIMA T graft was used in the majority of cases (88\%) for the left-sided lesions; a free RIMA was used only in $12 \%$ of the cases. A radial artery (RA) was used as a third arterial conduit in 67 patients (20\%), most commonly for the right-sided lesions, but in 16 cases was used for obtuse marginal territories.

The choice of conduits was decided upon patient baseline characteristics and anatomy and severity of the lesions. In general, BIMA is offered to young individuals ( $<65$ years old) with no more than 2 comorbidities out of diabetes, COPD and obesity.

LIMA was harvested following the semi-skeletonized technique whereas a fully skeletonized RIMA was preferred due to its optimized length and also to preserve some vascularization of the sternum. SVG was harvested either open or endoscopically, depending on availability of the appropriate trained personnel and resources. 
OPCAB strategy included routine opening of the right pleura to allow mobilization of the heart during the lateral wall exposure, placement of a deep pericardial string to facilitate the mobilization of the heart and use of a stabilizer (Maquet Acrobat ${ }^{\circledR}$ or Medtronic Octopus ${ }^{\circledR}$ ). Distal anastomoses were performed with temporary proximal vessel occlusion was undertaken to facilitate arteriotomy and intracoronary shunt insertion, following which vessel flow was restored and the distal anastomosis performed, with a bloodless field facilitated with a $\mathrm{CO}_{2}$ blower (Maquet AXIUS Blower Mister ${ }^{\circledR}$ ).

Proximal anastomoses, where necessary, were performed using either a partial occlusion aortic clamp or Heartstring Proximal Seal System (Maquet ${ }^{\circledR}$ ) where avoidance of aortic clamping was indicated.

The standard sequence of anastomoses consisted of distal anastomoses on the anterior wall (LAD, Diagonal), distal anastomoses on the inferior wall (RCA, PDA, LV branch), followed by proximal anastomoses (if applicable) and finally, anastomoses on the lateral wall (Intermediate, OM). If BIMA was used, the T-graft between LIMA-RIMA was constructed first and patency of the anastomosis tested.

\section{Statistical methods:}

Continuous variables were expressed as mean \pm standard deviation (SD) or median \pm inter-quartile range (IQR) (depending on distribution of data) and comparison between groups was performed using t test/ MannWhitney test. Categorical variables were expressed as percentages and compared using Chi-square/Fisher exact test as appropriate.

A multiple logistic regression model was used to identify the predictors of early mortality and Cox regression was applied to identify the best predictors of late mortality including all the significant variables listed in annexed tables (cut-off at $\mathrm{p}<0.05)$ (Tables 1-5). The results were expressed as odds ratios $(\mathrm{OR})$ and hazard ratios (HR) with corresponding $95 \%$ confidence intervals (CI).

As the two groups were significantly different with respect to their baseline characteristics, propensity score matching (with a match tolerance of 0.05) was performed (including the preoperative characteristic except echocardiographic parameters) using SPSS. The matched groups were analyzed using the methods described above.

Kaplan-Meier survival analysis was applied; curves were built for each group and were compared using the log-rank statistic.

SPSS 22.0 was used to analyze the data.

\section{Definitions:}

Previous neurologic disease: Cerebrovascular accident (CVA) or transient ischemic attack (TIA) diagnosed before the operation, with or without residual deficits.

Postoperative neurological events: new focal deficit after surgery; either TIA or CVA.

Long term ventilation: postoperative ventilation for more than 7 days, including reintubation or tracheostomy.

Respiratory complications: acute distress respiratory syndrome (ARDS) or pneumonia during the postoperative period.

Gastrointestinal (GI) complications: bowel ischemia, GI bleeding or laparotomy for any cause during the postoperative period.

Good LV: Ejection Fraction > 50\%.

Fair LV: Ejection Fraction $30-50 \%$.

Poor LV: Ejection Fraction $<30 \%$.

RESULTS 
Between 2003 and 2014 a total of 1210 patients underwent OPCAB in our institution under the same surgeon. One-vessel disease and other revascularization strategies different to SIMA or BIMA were excluded. We identified 1023 patients who fulfilled the inclusion criteria, 681 of them in the SIMA group and 382 in the BIMA group. As the two groups were significantly different with respect to their baseline characteristics, propensity score matching (with a match tolerance of 0.05) was performed, reducing the cohort to 684 patients.

BIMA was offered to younger patients (mean age $59.4 \pm 9.1$ vs. $69.4 \pm 7.7$ for the SIMA group, $\mathrm{p}=0.001$ ), predominantly male $(91 \%$ vs. $78 \%, \mathrm{p}=0.001)$ and with less comorbidities such as diabetes $(21 \%$ vs. $32 \%$, $\mathrm{p}=0.001)$, chronic obstructive respiratory disease $(\mathrm{COPD}, 10 \%$ vs. $17 \%, \mathrm{p}=0.002)$, previous neurological disease $(5 \%$ vs. $10 \%, \mathrm{p}=0.001)$, peripheral vascular disease $(10 \%$ vs. $19 \%, \mathrm{p}=0.001)$ or previous myocardial infarct $(45 \%$ vs. $55 \%, \mathrm{p}=0.005)$. Obesity $(\mathrm{BMI}>30)$ was similar in the two conduit strategies ( $40 \%$ vs. $44 \%, \mathrm{p}=0.07)$.

After the propensity matching, the baseline characteristics were comparable, although age remained significantly lower in the BIMA group (59.4 \pm 9.1 vs. $69.5 \pm 7.9, \mathrm{p}=0.001)$. (Table 1$)$ Rest of the preoperative characteristics for the non-matched and matched groups are listed in Table 1.

Revascularisation with BIMA was used for elective cases but also in-house urgent referrals (41\%) and emergency cases $(2 \%)$. Twenty-three patients had an intra-aortic balloon pump (IABP) inserted before the operation for unstable angina, and BIMA strategy was offered to three of them. After the propensity matching, the timing for surgery and use of preoperative IABP were also comparable. (Table 2)

The choice of conduits was not influenced by the extent of the disease. As determined by the preoperative coronary angiogram, the use of SIMA or BIMA was equivalent for three vessels disease $(83 \%$ vs. $80 \%, \mathrm{p}=$ $0.18)$, two vessels disease ( $17 \%$ vs. $20 \%, \mathrm{p}=0.18)$ and left main stem (LMS) disease $(32 \%$ vs. $37 \%, \mathrm{p}=$ 0.11). However, BIMA was most frequently used for patients with normal left ventricular ejection fraction (LVEF) ( $71 \%$ vs. $56 \%, \mathrm{p}=0.001)$ and less frequently in those in with impaired LVEF (Fair LVEF $27 \%$ vs. $38 \%$; Poor LVEF $2 \%$ vs. $6 \%, \mathrm{p}<0.05$ ). (Table 2 ). LVEF was also included in the propensity score matching, however the use of BIMA continued to seem to be preferred in patients with good LVEF and an adjusted Cox analysis was conducted to analyse the impact on survival. (Table 2)

Mean number of distal anastomoses performed was equivalent in the two groups, even before matching (SIMA $3.7 \pm 0.8(1-5)$, BIMA $3.7 \pm 0.8(2-6), \mathrm{p}=0.11)$. As expected, the number of arterial conduits used was superior in the BIMA group $(2.8 \pm 0.6(2-5))$ when compared to the SIMA group $(1.1 \pm 0.3(1-2)$, p $=0.001$; note that the patients recorded as two arterial conduits in the SIMA group had a sequential graft with the LIMA to the LAD and first diagonal). Venous conduits were more commonly used in the SIMA group $(2.5 \pm 0.8(0-4)$ vs. $0.8 \pm 0.8(0-3)$ in the BIMA group, $\mathrm{p}=0.001)$. A third arterial conduit $(\mathrm{RA})$ was used in 67 cases (20\%). Total arterial revascularization was achieved in 109 cases (42\%). (Table 3)

Complete revascularization was achieved in $99.4 \%$ of the cases; in the remaining $0.6 \%$, a vessel (PDA or $\mathrm{OM}$ ) was deemed to be too small to be grafted during the intraoperative analysis. The rate of conversion from $\mathrm{OPCAB}$ to ONCAB during the same period of the study was $0.7 \%$ ( 8 cases, which were excluded from the study). Reasons for conversion were: ventricular arrhythmias (4 cases), intraoperative cardiac arrest (2 cases) or difficult exposure of an intramyocardial OM vessel (2 cases).

\section{In-hospital results}

The results analyzed correspond to the matched groups. The non-matched group results are displayed in the corresponding tables but are not commented in the manuscript.

Overall in-hospital mortality was $1.3 \%$ (9 cases). The cause of death was: cardiac (4 cases, $44 \%)$, sepsis (3 cases, $34 \%$ ), neurological (1 case, $11 \%)$, and respiratory (1 case, $11 \%)$. In-hospital mortality was similar in the two groups: SIMA $2 \%$, BIMA $1 \%(\mathrm{p}=0.18)$. (Table 4$)$

The multivariate regression model identified previous hemodialysis $(\mathrm{p}=0.02$, OR 0.03, CI 95\% 0.1-0.5) as 
risk factor for in-hospital mortality.

Complications in the immediate postoperative period were equivalent in the two groups, except for neurological complications $(1 \%$ vs. $0 \%, \mathrm{p}=0.05)$ and leg wound infection $(4 \%$ vs. $1 \%, \mathrm{p}=0.001)$, which were significantly higher in the SIMA group (Table 4). The incidence of DSWI was only $2 \%$ (17 patients) and was equivalent in the two groups. Of those, 10 patients were treated conservatively and, only 7 (1\%) required reoperation for wound debridement and/or resuturing. (Table 4)

Postoperative neurological complications $(\mathrm{p}=0.002$, OR 8.9, CI 95\% $5.1-13.8)$ and postoperative hemofiltration ( $\mathrm{p}=0.001$, OR 36.9, CI $4.9-27.6)$ were identified by the multivariate regression model as risk factors for in-hospital mortality.

\section{Follow-up results}

Long-term mortality was obtained from the National Demographic Census with a $100 \%$ completion of data. Overall, $13 \%$ of the patients died during the follow-up period. The causes of death were as follows: Cardiac $35 \%$, Neurological 13\%, Cancer 8\%, Renal 7\%, Respiratory 7\%, Sepsis 6\%, Vascular 1\%, Gastrointestinal $1 \%$ and Other $7 \%$. We were unable to identify the cause of death in $15 \%$ of the cases.

Overall one-year mortality was $2 \%$. It was $2 \%$ in the SIMA group and $1 \%$ in the BIMA group ( $=0.22)$. Overall five-year mortality was $10 \%$ and in this case it was significantly higher in the SIMA group (16\% vs. $5 \%, \mathrm{p}<0.001$ ). (Table 5 )

Age $(\mathrm{p}=0.001$, HR 1.1, 95\% CI $1.1-1-2)$, COPD ( $\mathrm{p}=0.004$, HR 2.0, 95\% CI 1.2-3.2) and Logistic EuroScore $(\mathrm{p}=0.002$, HR 1.0, $95 \%$ CI 1.1- 1.2) were identified by the Cox regression as risk factors for long-term mortality.

Mean survival calculated by the Kaplan-Meier curve was $11.0 \pm 0.2$ years (95\% CI $10.7-11.4)$ in the BIMA group and $10.0 \pm 0.3$ years $(95 \%$ CI $9.5-10.6)$ in the SIMA group.

The Kaplan-Meier survival curves and number of patients at risk for each period are displayed in Figure 1 and annexed table. The survival curve for the non-matched population is displayed in Figure 2.

Since the two groups still differed in age, with the BIMA group having significantly younger patients, a Cox model was applied to account the age difference. Subjects who received BIMA still had better survival compared to those who received SIMA (HR 0.63 (0.4-0.99), p 0.047).

The Cox analysis was also applied to the LV function subgroups, as they remained significantly different after the propensity matching. BIMA conferred a survival benefit for patients with good LVEF (HR 0.31 $(0.18-0.54), \mathrm{p}=0.0001)$ and fair LVEF (HR $0.54(0.3-0.99), \mathrm{p}=0.048)$, but we did not demonstrate a significant survival benefit when using BIMA for patients with poor LVEF (HR 1.61 (0.27 - 9.59, p = 0.6).

The follow-up visits and/or telephone interview revealed an excellent functional class years after the operation. Only $8 \%$ of the patients reported residual angina being in CCS class II - III and $4 \%$ of the patients described dyspnea in NYHA Class III-IV, which was more likely attributed to concomitant aortic stenosis or advanced COPD. The incidence of myocardial and cerebrovascular events during the following years after the operation was $3 \%$. There were no differences in the distribution of the complications or residual symptoms amongst the groups.

Thirty-two patients $(6 \%)$ were lost to follow-up. (Table 6)

Thirty-nine patients $(7 \%)$ underwent a repeated angiogram years after the operation. The most common reason was residual angina, although $20 \%$ of them were done as part of the preoperative workup due to severe aortic stenosis.

The angiogram confirmed patent grafts in $36 \%$ of the cases. Graft failure was reported in $33 \%$ cases (13 patients), most commonly due to the SV graft failure (62\%, 8 cases) but arterial grafts were also affected (LIMA 15\%, 2 cases; RIMA 15\%, 2 cases; RA 8\%, 1 case). Two patients showed combination of venous and 
arterial graft failure. In $8 \%$ of the cases (3 patients), the angiogram showed progression of the native disease in vessels not previously grafted, and in $15 \%$ of the cases (6 patients) we were not able to determine the result since the angiogram was not performed in our institution but in a local hospital.

Only 17 patients (5\%) required further revascularization with PCI, and only $0.4 \%$ of them were required during the first year after the operation. (Table 6)

\section{DISCUSSION}

Several observational studies and meta-analysis have reported the survival advantage when using BIMA compared to SIMA, even in diabetics and elder populations. ${ }^{[1-8]}$ The survival advantage seems to increase through the postoperative years, even beyond 15 years. ${ }^{[9-10]}$ These studies have also reported equivalent results in terms of mortality and morbidity after the use of BIMA when compared to SIMA, therefore raising the question of why the routine use of BIMA is not standard practice.

Our study confirmed the survival advantage of BIMA compared to SIMA and the absence of extra complications or in-hospital mortality excess when the BIMA is used.

The only RCT to date, the Arterial Revascularization Trial (ART), which reported recently their 10-years results has not been able to demonstrate a survival benefit with the use of BIMA at one, five or ten years. Our mortality result using BIMA is significantly lower that the results reported in the ART trial (1\% vs. $2.5 \%$ at 1 year and $5 \%$ vs. $8.7 \%$ at 5 years). ${ }^{[11-13]}$

They also reported a repeated revascularization rate of $1.8 \%$ at one-year for the BIMA group and $1.3 \%$ for the SIMA group. ${ }^{[11-13]}$ We have demonstrated a lower repeated revascularization rate, especially at one-year $(0.4 \%)$, which is even more impressive if we take on account that we are reporting OPCAB surgery, which has always had slightly higher rates of reported repeated revascularization (1.4\% at one-year in the CORONARY trial, $4.6 \%$ at one-year in the ROOBY trial). ${ }^{[25,26]}$

A subanalysis of the ART comparing 5-years outcomes of the two revascularization strategies used in their trial (ONCAB and OPCAB) did not demonstrate any significant differences between the two of them. They report $8 \%$ five-year mortality for both strategies, while we reported an overall 5-year mortality of $10 \%$, significantly higher in the SIMA group $(16 \%$ vs. $5 \%, \mathrm{p}<0.001)$. ${ }^{[15]}$

One of the main limitations for the routine use of BIMA has been the high reported rate of DSWI. In our study, the incidence of DSWI was only $2 \%$. The incidence of sternal reconstruction in our series was only $1 \%$, lower than the ART study, that reported a $1.9 \%$ sternal wound reconstruction in the BIMA group and $0.6 \%$ in the SIMA group at one-year. Our lower rates are consistent with the lower rates of DSWI expected for patients undergoing BIMA harvesting in the OPCAB setting. ${ }^{[11-16]}$

It has been reported that the skeletonized technique reduces the risk of DSWI without compromising the long-term graft patency. ${ }^{[16]}$ The ART trial suggested, that the use of bilateral skeletonized BIMA has the same risk of DSWI than a pedicle SIMA. ${ }^{[12]}$ Our strategy for harvesting mammary arteries consists on semi-skeletonize the LIMA and completely skeletonize the RIMA.

The optimal configuration of BIMA grafts is unknown. A number of grafting strategies have been described, including bilateral grafts in situ, use of the RIMA as a free graft from the aorta and the creation of $\mathrm{T}$ or Y composite grafts from the LIMA. None of them seem to be superior in terms of survival or long-term patency. ${ }^{[17,18]}$

In our center, the initial use of free RIMA has declined in favor of the current strategy of $\mathrm{T}$ composite grafts between LIMA and RIMA.

The routine use of BIMA is still very limited. Despite the clear survival benefit and the equivalent in-hospital complications, it is not offered to all patients. Some advocated reasons are the technical skills required for harvesting and grafting, the increased operating time and resources, the lack of consensus for selection of patients whom can benefit most and the higher rate of DSWI. 
In our institution, we believe that the technical aspects can be taught, and we include them in our training program. However, the lack of consensus for selection criteria is important and at present, we only offer BIMA to certain patients based on the individual surgeon's own selection criteria.

The use of the radial artery (RA) is still generating debate. Several studies had tried to compare it to BIMA. A meta-analysis confirmed the survival benefit of the BIMA also versus SIMA-RA. ${ }^{[21]}$ On the other hand, a similar benefit to BIMA when using a SIMA-RA composite but obviously, eliminating the extra risk of DSWI has also been recently reported. ${ }^{[22]}$

Furthermore, when analyzed as a third arterial conduit, the use of a RA has not shown to add any survival benefit. $[23,24]$

In our study, the radial artery was used only in $20 \%$ of the cases, mostly in the initial years of the study. The current practice of the author is to use the BIMA for the left-sided lesions and a SV conduit for the right-sided lesions, reserving RA for when there are no other conduits available.

Our study has the limitations of being retrospective and purely descriptive. We report a single surgeon experience with a level of expertise reflected in a greater number of distal anastomoses and lower rate of conversion and incomplete revascularization compared to the historical OPCAB RCTs, but with the uncertainty of the feasibility of extrapolating these results to other surgical practice.

\section{CONCLUSIONS}

We conclude, from our results, that the use of BIMA in coronary revascularization offers a long-term survival benefit compared to SIMA, and that the use of BIMA does not increase the rate of postoperative complications, including deep sternal wound infection.

Excellent outcome can be achieved with OPCAB BIMA in real world practice with adequate patient selection.

\section{BACK MATTER}

\subsection{Authors contributions}

Lopez-Marco A and Mehta D made substantial contribution to conception and design of the study. The data acquisition was performed by Lopez-Marco A and Syed A. Phillips M, Williams J, George J, Hogan J and Mansoor J contribution consisted on conducting the follow-up interviews and collecting that pertinent data. The data analysis and interpretation was done by Lopez-Marco A, along with the expertise of the statistician Ghebre M.

\subsection{Financial support and sponsorship}

No funding was received for this study. No conflict of interest with industry to declare.

\subsection{Conflicts of interest}

All authors declare that there are no conflicts of interest.

4.4. EthicaThis study was approved by the institutional Health Board. An individual consent form from every patient was deemed not necessary as the study was retrospective and the data was kept anonymised.

\section{REFERENCES}

1. Weiss AJ, Zhao S, Tian DH, Taggart DP, Yan TD. A meta-analysis comparing bilateral mammary artery with left internal mammary artery for coronary artery bypass grafting. Ann Cardiothorac Surg 2013;2(4):390-400.

2. Benedetto U, Amrani M, Gaer J, Bahrami T, de Robertis F, Simon AR et al. The influence of bilateral internal mammary arteries on short- and long-term outcomes: A propensity score matching in accordance with current recommendations. J Thorac Cardiovasc Surg 2014; 148(6):2699-705 
3. Takagi H, Goto SN, Watanabe T, Mizuno Y, Kawai N, Umemoto T. A meta-analysis of adjusted hazard ratios from 20 observational studies of bilateral versus single internal thoracic artery coronary artery bypass grafting. J Thorac Cardiovasc Surg 2014;148(4):1282-90.

4. Sa MP, Ferraz PE, Escobar RR, Vasconcelos FP, Ferraz AA, Braile DM, et al. Skeletonized versus pedicled internal thoracic artery and risk of sternal wound infection after coronary bypass surgery: meta-analysis and meta- regression of 4817 patients. Interact Cardiovasc Thorac Surg. 2013;16(6):84957.

5. Kurlansky PA. Traad EA, Dorman MJ, Galbut DL, Ebra G. Bilateral versus single internal mammary artery grafting in the elderly: long-term survival benefit. Ann Thorac Surg 2015;100(4):1374-81.

6. Kajimoto K, Yamamoto T, Amano A. Coronary artery bypass revascularization using bilateral internal thoracic arteries in diabetic patients: a systematic review and meta-analysis. Ann Thorac Surg, 2015;99(3):1097-104.

7. Kinoshita T, Asai T, Suzuki T, Kuroyanagi S, Hosoba S, Takashima N et al. Off-pump bilateral skeletonized internal thoracic artery grafting in elderly patients. Ann Thorac Surg 2012;93:531-6.

8. Grau JB, Ferrari G, Mak AWC, Shaw RE, Brizzio ME, Mindich BP et al. Propensity matched analysis of bilateral internal mammary artery versus single left internal mammary artery grafting at 17-year follow-up: validation of a contemporary surgical experience. E J Cardiothorac Surg 2012;41(4):770-776.

9. Kurlanksy PA, Traad EA, Dorman MJ, Galbut DL, Zucker M, Ebra G. Thirty-year follow-up defines survival benefit for second internal mammary artery in propensity-matched groups. Ann Thorac Surg 2010;90:101-8.

1. Lytle BW, Blackstone EH, Sabik JF, Houghtaling P, Loop FD, Cosgrove DM. The effect of bilateral internal thoracic artery grafting on survival during 20 postoperative years. Ann Thorac Surg 2004;78:2005-14.

2. Taggart DP, Altman DG, Gray AM, Lees B, Nugara F, Yu LM et al. Effects of on-pump and off-pump surgery in the Arterial Revascularization Trial. Eur J Cardiothorac Surg 2015;47(6):1059-65.

3. Taggart DP, Altman DG, Gray AM. Lees B, Nugara F, Yu LM et al. Randomized trial to compare bilateral vs. internal mammary coronary artery bypass grafting: 1-year results for the Arterial Revascularisation Trial (ART). Eur Heart J 2010;31:2470-81.

4. Taggart DP, Altman DG, Gray AM. Lees B, Gerry S, Benedetto U et al. Randomized trial of bilateral versus single internal-thoracic artery grafts. N Engl J Med, 2016;375:2540-2549.

5. Taggart DP. Benedetto U, Gerry S, Altman DG, Gray AM, Lees Bet al. Bilateral versus single internalthoracic artery grafts at 10 years. M Engl J Med 2019; 380:43-446.

6. Benedetto U, Altman DG, Gerry S, Gray A, Lees B, Flather M et al. Off-pump versus on-pump coronary artery bypass grafting: Insight from the Arterial Revascularisation Trial. J Thorac Cardiovasc Surg 2018;155:1545-53).

7. Benedetto U, Altman DG, Gerry S, Gray A, Lees B, Pawlaczyk P et al. Pedicled and skeletonized single and bilateral internal thoracic artery grafts and the incidence of sternal wound complications: Insights from the Arterial Revascularization Trial. J Thorac Cardiovas Surg 2016; 152:270-6.

8. Raja SG. Surgical strategies for bilateral internal mammary artery grafting. Int J Surg 2015(16);140145 .

9. Robinson BM, Paterson HS, Naidoo R, Dhurandhar V, Denniss AR. Bilateral internal thoracic artery composite Y grafts: analysis of 464 angiograms in 296 patients. Ann Thorac Surg 2016;101:974-80.

10. Umakanthan J, Jeyakumar P, Umakanthan B, Jeyakumar N, Senthilkumar N, Saraswathy MR et al. Barriers to the universal adoption of bilateral internal mammary artery grafting. Int J Surg 2015:16;179182

11. LaPar DJ, Crosby IK, Rich JB, Quader MA, Speir AM, Kern JA et al. Bilateral internal mammary artery use for coronary artery bypass grafting remains underutilized: a propensity-matched multiinstitution analysis. Ann Thorac Surg 2015;100:8-15.

12. Benedetto U, Gaudino M, Caputo M, Tranbaugh RF, Lau C, Di Franco A et al. Right internal thoracic artery versus radial artery as the second best arterial conduit: Insights from a meta-analysis of propensity-matched data on long-term survival. J Thorac Cardiovasc Surg, 2016; 152:1083-91. 
13. Pevni D, Mohr R, Paz Y, Kramer A, Ben-Gal Y, Nesher N et al. Long-term outcome of revascularization with composite T-grafts: Is bilateral mammary grafting better than single mammary and radial artery grafting? J Thorac Cardiovasc Surg 2016;151:1311-1319.

14. Benedetto U, Caputo M, Zakkar M, Bryan A, Angelini GA. Are three arteries better than two? Impact of using the radial artery in addition to bilateral internal thoracic artery grafting on long-term survival. J Thorac Cardiovasc Surg, 2016

15. Mohammadi S, Dagenais F, Voisine P, Dumont E, Charbonneau E, Marzouk M et al. Impact of the radial artery as and additional arterial conduit during in-situ bilateral internal mammary artery grafting: a propensity score-matched study. Ann Thorac Surg 2016;101:913-8.

16. Lamy A, Deverauz PJ, Prabhakaran D, Taggart DP, Hu S, Paolasso E et al. Effects of off-pump and on-pump coronary artery bypass grafting at 1 year. N Engl J Med 2013; 368:1179-1188.

17. Shroyer Al, Grover FL, Hattler B, Collins JF, McDonald GO, Kozora E et al. On-pump versus off-pump coronary-artery bypass surgery. N Engl J med 2009; 361:1824-1837.

\section{TABLES}

Table 1. Preoperative characteristics

\begin{tabular}{|c|c|c|c|c|c|c|}
\hline & SIMA & BIMA & $\mathrm{P}$ & SIMA matched & BIMA matched & $\mathrm{P}$ \\
\hline & $\mathrm{n}=681$ & $\mathrm{n}=342$ & & $\mathrm{n}=342$ & $\mathrm{n}=342$ & \\
\hline Age & $69.4 \pm 7.7(38-85)$ & $59.4 \pm 9.1(34-85)$ & 0.001 & $69.5 \pm 7.9(40-87)$ & $59.4 \pm 9.1(34-85)$ & 0.001 \\
\hline Female & $147(22 \%)$ & $31(9 \%)$ & 0.001 & $29(8 \%)$ & $31(9 \%)$ & 0.89 \\
\hline Angina CCS II-III & $269(39 \%)$ & $117(34 \%)$ & 0.1 & $110(32 \%)$ & $117(34 \%)$ & 0.63 \\
\hline NYHA III-IV & $167(24 \%)$ & $60(17 \%)$ & 0.01 & $58(17 \%)$ & $60(17 \%)$ & 0.92 \\
\hline Hypertension & $540(79 \%)$ & $230(67 \%)$ & 0.001 & $243(71 \%)$ & $230(67 \%)$ & 0.32 \\
\hline Diabetes & $216(32 \%)$ & $73(21 \%)$ & 0.001 & $76(22 \%)$ & $73(21 \%)$ & 0.85 \\
\hline Hypercholesterolaemia & $613(90 \%)$ & $301(88 \%)$ & 0.33 & $310(91 \%)$ & $301(88 \%)$ & 0.32 \\
\hline Family history IHD & $405(59 \%)$ & $242(71 \%)$ & 0.001 & $201(59 \%)$ & $242(71 \%)$ & 0.001 \\
\hline Smoking history & $451(66 \%)$ & $242(71 \%)$ & 0.14 & $221(65 \%)$ & $242(71 \%)$ & 0.10 \\
\hline Previous MI & $378(55 \%)$ & $154(45 \%)$ & 0.005 & $172(50 \%)$ & $154(45 \%)$ & 0.19 \\
\hline Previous PCI & $58(8 \%)$ & $38(11 \%)$ & 0.24 & $34(10 \%)$ & $38(11 \%)$ & 0.71 \\
\hline Previous surgery & $5(1 \%)$ & $2(1 \%)$ & 0.72 & $2(1 \%)$ & $2(1 \%)$ & 0.99 \\
\hline Atrial fibrillation & $42(6 \%)$ & $8(2 \%)$ & 0.01 & $6(2 \%)$ & $8(2 \%)$ & 0.79 \\
\hline COPD & $116(17 \%)$ & $34(10 \%)$ & 0.002 & $32(9 \%)$ & $34(10 \%)$ & 0.89 \\
\hline CVA/TIA & $71(10 \%)$ & $18(5 \%)$ & 0.001 & $18(5 \%)$ & $18(5 \%)$ & 0.99 \\
\hline Hemodialysis & $12(2 \%)$ & $2(1 \%)$ & 0.13 & $6(2 \%)$ & $2(1 \%)$ & 0.29 \\
\hline Carotid disease & $34(5 \%)$ & $9(3 \%)$ & 0.08 & $8(2 \%)$ & $9(3 \%)$ & 0.99 \\
\hline PVD & $133(19 \%)$ & $35(10 \%)$ & 0.001 & $38(11 \%)$ & $35(10 \%)$ & 0.81 \\
\hline DVT & $9(1 \%)$ & $3(1 \%)$ & 0.53 & $6(2 \%)$ & $9(3 \%)$ & 0.62 \\
\hline Varicose veins & $124(18 \%)$ & $58(17 \%)$ & 0.001 & $56(16 \%)$ & $58(17 \%)$ & 0.78 \\
\hline Obesity & $272(40 \%)$ & $151(44 \%)$ & 0.07 & $124(36 \%)$ & $147(43 \%)$ & 0.24 \\
\hline BMI & $29.2 \pm 4.7(15-49)$ & $29.2 \pm 4.5(19-65)$ & 0.33 & $29.69 \pm 4.5(20-49)$ & $29.2 \pm 5.5(19-65)$ & 0.72 \\
\hline
\end{tabular}

Preoperative characteristics in patients who underwent isolated OPCAB using single or bilateral internal mammary arteries. Results displayed for the non-matched and matched populations. BIMA: Bilateral Internal Mammary Artery; BMI: Body Mass Index; CCS: Angina Canadian Cardiovascular Society Angina score; COPD: Chronic Obstructive Pulmonary Disease; CVA: Cerebral vascular accident; DVT: Deep Venous Thrombosis; IHD: Ischemic Heart Disease; MI: Myocardial Infarct; NYHA: New York Heart Association Dyspnea Score; PCI: Percutaneous Coronary Intervention; PVD: Peripheral Vascular Disease; SIMA: Single Internal Mammary Artery; TIA: Transient Ischemic Attack

Table 2. Extent of coronary disease and timing of surgery 


\begin{tabular}{lllllll}
\hline & SIMA & BIMA & P & SIMA matched & BIMA matched & P \\
\hline & $\mathrm{n}=681$ & $\mathrm{n}=342$ & & $\mathrm{n}=342$ & $\mathrm{n}=342$ & \\
LMS & $219(32 \%)$ & $127(37 \%)$ & 0.11 & $108(31 \%)$ & $127(37 \%)$ & 0.15 \\
$2 \mathrm{VD}$ & $114(17 \%)$ & $69(20 \%)$ & 0.18 & $63(18 \%)$ & $69(20 \%)$ & 0.66 \\
$3 \mathrm{VD}$ & $567(83 \%)$ & $273(80 \%)$ & 0.18 & $279(81 \%)$ & $273(80 \%)$ & 0.66 \\
Good LV & $384(56 \%)$ & $240(71 \%)$ & 0.001 & $206(60 \%)$ & $240(70 \%)$ & 0.008 \\
Fair LV & $258(38 \%)$ & $94(27 \%)$ & 0.001 & $119(35 \%)$ & $94(27 \%)$ & 0.05 \\
Poor LV & $39(6 \%)$ & $8(2 \%)$ & 0.01 & $17(5 \%)$ & $8(2 \%)$ & 0.10 \\
In-house & $319(47 \%)$ & $141(41 \%)$ & 0.05 & $153(45 \%)$ & $141(41 \%)$ & 0.44 \\
Emergency & $23(3 \%)$ & $6(2 \%)$ & 0.05 & $3(1 \%)$ & $3(1 \%)$ & 0.99 \\
Preoperative IABP & $20(3 \%)$ & $3(1 \%)$ & 0.04 & $3(1 \%)$ & $3(1 \%)$ & 0.95 \\
Logistic EuroScore & $6.1 \pm 8.0(1-61)$ & $4.7 \pm 8.5(1-60)$ & 0.43 & $5.1 \pm 7.2(1-53)$ & $4.7 \pm 8.5(1-60)$ & 0.64 \\
\hline
\end{tabular}

Extent of coronary disease, preoperative ventricular function and timing of the surgery in patients who underwent isolated OPCAB using single or bilateral internal mammary arteries (BIMA). Results displayed for the non-matched and matched populations. BIMA: Bilateral Internal Mammary Artery; IABP: IntraAortic Balloon Pump; LMS: Left Main Stem, LV: Left Ventricle; SIMA: Single Internal Mammary Artery; VD: Vessels Disease.

Table 3. Revascularisation strategy

\begin{tabular}{|c|c|c|c|c|c|c|}
\hline & SIMA & BIMA & $\mathrm{P}$ & SIMA matched & BIMA matched & $\mathrm{P}$ \\
\hline & $\mathrm{n}=681$ & $\mathrm{n}=342$ & & $\mathrm{n}=342$ & $\mathrm{n}=342$ & \\
\hline Distal anastomosis & $3.7 \pm 0.8(1-5)$ & $3.7 \pm 0.8(2-6)$ & 0.11 & $3.7 \pm 0.8(1-5)$ & $3.6 \pm 0.9(2-6)$ & 0.06 \\
\hline Arterial grafts & $1.1 \pm 0.3(1-2)$ & $2.8 \pm 0.6(2-5)$ & 0.001 & $1.2 \pm 0.4(1-2)$ & $2.8 \pm 0.7(2-5)$ & 0.001 \\
\hline Venous grafts & $2.5 \pm 0.8(0-4)$ & $0.8 \pm 0.8(0-3)$ & 0.001 & $2.5 \pm 0.8(0-4)$ & $0.8 \pm 0.8(0-3)$ & 0.001 \\
\hline SIMA & $681(100 \%)$ & 0 & 0.001 & $262(100 \%)$ & 0 & 0.001 \\
\hline 2nd arterial graft (BIMA) & 0 & $342(100 \%)$ & 0.001 & 0 & $342(100 \%)$ & 0.001 \\
\hline 3rd arterial graft (BIMA/RADIAL) & 0 & $67(20 \%)$ & 0.001 & 0 & $67(20 \%)$ & 0.001 \\
\hline Total arterial & 0 & $109(42 \%)$ & 0.001 & 0 & $148(42 \%)$ & 0.001 \\
\hline Incomplete revascularisation & $3(1 \%)$ & 0 & 0.08 & $1(0.3 \%)$ & 0 & 0.99 \\
\hline
\end{tabular}

Revascularization strategy in patients who underwent isolated OPCAB using single or bilateral internal mammary arteries. Results displayed for the non-matched and matched populations. BIMA: Bilateral Internal Mammary Artery; SIMA: Single Internal Mammary Artery

Table 4. Postoperative complications

\begin{tabular}{lllllll}
\hline & SIMA & BIMA & P & SIMA matched & BIMA matched & P \\
\hline & $\mathrm{n}=681$ & $\mathrm{n}=342$ & & $\mathrm{n}=342$ & $\mathrm{n}=342$ & \\
Reoperation for bleeding & $17(2 \%)$ & $3(1 \%)$ & 0.08 & $9(3 \%)$ & $3(1 \%)$ & 0.14 \\
Reoperation for DSWI & $8(1 \%)$ & $3(1 \%)$ & 0.67 & $4(1 \%)$ & $3(1 \%)$ & 0.99 \\
Postoperative CVA/TIA & $9(1 \%)$ & 0 & 0.4 & $5(1 \%)$ & 0 & 0.07 \\
Postop hemofiltration & $33(5 \%)$ & $12(3 \%)$ & 0.3 & $9(3 \%)$ & $8(2 \%)$ & 0.99 \\
Deep sternal wound infection & $17(2 \%)$ & $8(2 \%)$ & 0.9 & $9(3 \%)$ & $8(2 \%)$ & 0.76 \\
Atrial fibrillation & $157(23 \%)$ & $51(15 \%)$ & 0.01 & $78(23 \%)$ & $51(15 \%)$ & 0.01 \\
Pneumonia/ARDS & $15(2 \%)$ & $4(1 \%)$ & 0.25 & $8(2 \%)$ & $4(1 \%)$ & 0.38 \\
Prolonged ventilation/Tracheostomy & $8(1 \%)$ & $2(1 \%)$ & 0.37 & $5(1 \%)$ & $2(1 \%)$ & 0.45 \\
Chest infection & $62(9 \%)$ & $22(6 \%)$ & 0.14 & $31(9 \%)$ & $22(6 \%)$ & 0.25
\end{tabular}




\begin{tabular}{lllllll}
\hline & SIMA & BIMA & P & SIMA matched & BIMA matched & P \\
\hline Sepsis & $4(1 \%)$ & $21 \%)$ & 0.99 & $3(1 \%)$ & $2(1 \%)$ & 0.99 \\
Leg wound infection & $28(4 \%)$ & $2(1 \%)$ & 0.9 & $14(4 \%)$ & $2(1 \%)$ & 0.005 \\
Pacemaker/ICD insertion & $6(1 \%)$ & $2(1 \%)$ & 0.91 & $3(1 \%)$ & $1(0.3 \%)$ & 0.27 \\
GI complications & $17(2 \%)$ & $5(2 \%)$ & 0.02 & $6(2 \%)$ & $5(1 \%)$ & 0.99 \\
Hospital mortality & $16(2 \%)$ & $2(1 \%)$ & 0.05 & $7(2 \%)$ & $2(1 \%)$ & 0.18 \\
\hline
\end{tabular}

Postoperative complications in patients who underwent isolated OPCAB using single or bilateral internal mammary arteries. Results displayed for the non-matched and matched populations. ARDS: Acute Respiratory Distress Syndrome; BIMA: Bilateral Internal Mammary Artery; CVA: Cerebrovascular Accident; DSWI: Deep Sternal Wound Infection; GI: Gastrointestinal; ICD: Implantable Cardioverter Defibrillator; SIMA: Single Internal Mammary Artery; TIA: Transient Ischemic Attack

Table 5. Long-term survival

\begin{tabular}{lllllll}
\hline & SIMA & BIMA & P & SIMA matched & BIMA matched & P \\
\hline & $\mathrm{n}=681$ & $\mathrm{n}=342$ & & $\mathrm{n}=342$ & $\mathrm{n}=342$ & \\
Late mortality & $162(24 \%)$ & $34(10 \%)$ & 0.001 & $72(21 \%)$ & $34(10 \%)$ & 0.001 \\
One-year mortality & $22(3 \%)$ & $3(1 \%)$ & 0.06 & $8(2 \%)$ & $3(1 \%)$ & 0.22 \\
One-year survival & $639(97 \%)$ & $326(99 \%)$ & 0.06 & $320(98 \%)$ & $326(99 \%)$ & 0.22 \\
Five-year mortality & $82(17 \%)$ & $14(5 \%)$ & 0.001 & $40(16 \%)$ & $14(5 \%)$ & 0.001 \\
Five-year survival & $403(83 \%)$ & $256(95 \%)$ & 0.001 & $210(84 \%)$ & $256(95 \%)$ & 0.001 \\
\hline
\end{tabular}

Long-term survival in patients who underwent isolated OPCAB using single or bilateral internal mammary arteries. Results displayed for the non-matched and matched populations.

BIMA: Bilateral Internal Mammary Artery; SIMA: Single Internal Mammary Artery

Table 6. Follow-up events

\begin{tabular}{lllllll}
\hline & SIMA & BIMA & $\mathrm{P}$ & SIMA matched & BIMA matched & $\mathrm{P}$ \\
\hline & $\mathrm{n}=519$ & $\mathrm{n}=306$ & & $\mathrm{n}=263$ & $\mathrm{n}=306$ & \\
Angina CCS II-III & $37(7 \%)$ & $29(9 \%)$ & 0.06 & $15(6 \%)$ & $29(9 \%)$ & 0.06 \\
NYHA III-IV & $28(5 \%)$ & $9(3 \%)$ & 0.23 & $13(5 \%)$ & $9(3 \%)$ & 0.45 \\
CVA/TIA & $16(3 \%)$ & $8(3 \%)$ & 0.34 & $9(3 \%)$ & $8(3 \%)$ & 0.92 \\
Myocardial infarct & $13(2 \%)$ & $10(3 \%)$ & 0.23 & $6(2 \%)$ & $11(4 \%)$ & 0.51 \\
Re-angiogram & $35(7 \%)$ & $26(9 \%)$ & 0.13 & $13(5 \%)$ & $26(9 \%)$ & 0.07 \\
Patent grafts & $14(2 \%)$ & $7(2 \%)$ & 0.3 & $6(2 \%)$ & $8(3 \%)$ & 0.13 \\
PCI & $11(2 \%)$ & $10(3 \%)$ & 0.13 & $6(2 \%)$ & $11(4 \%)$ & 0.4 \\
Missing & $1(0.1 \%)$ & $32(10 \%)$ & & 0 & $32(10 \%)$ & \\
\hline
\end{tabular}

Follow-up events in patients who underwent isolated OPCAB using single or bilateral internal mammary arteries. Results displayed for the non-matched and matched populations.

BIMA: Bilateral Internal Mammary Artery; CCS: Canadian Cardiovascular Society Angina score; CVA: Cerebrovascular Accident; NHYA: New York Heart Association Dyspnea score; PCI: Percutaneous Coronary Intervention; SIMA: Single Internal Mammary Artery; TIA: Transient Ischemic Attack

\section{FIGURE LEGENDS}


Figure 1: Kaplan Meier survival curve in patients who underwent isolated OPCAB using single (SIMA) or bilateral internal mammary arteries (BIMA). Results displayed for the matched populations. The number of patients at risk at each point is displayed in the table.

\begin{tabular}{llllll}
\hline Years & 2 & 4 & 6 & 8 & 10 \\
\hline BIMA & 313 & 278 & 235 & 169 & 91 \\
SIMA & 303 & 252 & 172 & 107 & 51 \\
\hline
\end{tabular}

Figure 2: Kaplan Meier survival curve in patients who underwent isolated OPCAB using single (SIMA) or bilateral internal mammary arteries (BIMA). Results displayed for the non-matched population. The number of patients at risk at each point is displayed in the table.

\begin{tabular}{llllll}
\hline Years & 2 & 4 & 6 & 8 & 10 \\
\hline BIMA & 304 & 263 & 217 & 155 & 72 \\
SIMA & 574 & 443 & 311 & 180 & 80 \\
\hline
\end{tabular}

